\title{
Sore Throat
}

National Cancer Institute

\section{Source}

National Cancer Institute. Sore Throat. NCI Thesaurus. Code C50747.

Any kind of inflammatory process of the tonsils, pharynx, or/and larynx characterized by pain in swallowing. 